\title{
Mating Signals Control Expression of both Starch Fermentation Genes and a Novel Flocculation Gene FLO8 in the Yeast Saccharomyces
}

\author{
Ichiro Yamashita and Sakuzo FuKUI \\ Department of Fermentation Technology, Faculty of Engineering, \\ Hiroshima University, \\ Shitami, Saijo-cho, Higashi-Hiroshima 724, Japan \\ Received July 11, 1983
}

\begin{abstract}
In the yeast Saccharomyces diastaticus, expression of both glucoamylase-producing (STA) genes and a novel flocculation gene $F L O 8$ was greatly diminished by the mating-type locus $M A T a /$ $M A T \alpha$.
\end{abstract}

In 1978, H. Tamaki isolated three polymorphic genes (STA1, STA2, and STA3) for starch fermentation in the yeast Saccharomyces diastaticus ${ }^{1)}$ and demonstrated that haploid strains of $S$. diastaticus carrying any one of the unlinked $S T A$ genes produce one of the extracellular glucoamylase isozymes I, II, and III. ${ }^{2}$ Recently we observed that the glucoamylase production was greatly diminished in diploid strains that are homozygous for the $S T A$ genes but are heterozygous for the co-dominant mating-type alleles $M A T a$ and $M A T \alpha$. However, full expression of the producing ability was recovered in diploid strains homozygous for both $S T A$ and $M A T$.

Flocculation genes are widely distributed in the yeast Saccharomyces cerevisiae, which is very closely allied to $S$. diastaticus. ${ }^{3)}$ Flocculation has been studied mostly with brewer's strains of yeasts because of its importance to the brewing industry. ${ }^{4,5)} \mathrm{We}$ isolated a novel flocculation gene, $F L O 8$, from $S$. diastaticus strain $5106-32 \mathrm{D}$, provided by $\mathrm{H}$. Tamaki. The FLO8 gene is loosely linked to arg4 on chromosome VIII, and details about this gene will be published elsewhere (manuscript submitted). Diploid strains heterozygous for FLO8 but homozygous for MAT were flocculent, indicating a dominant phenotype of the FLO8 gene, but diploid strains heterozygous for both FLO8 and MAT were non-

\section{flocculent.}

In this communication, we describe how the expression of two $S T A$ genes ( $S T A 1$ and $S T A 3)$ and the flocculation gene FLO8 is controlled by the constitution of the matingtype locus. A preliminary report of this work was presented at the Annual Meeting of the Agricultural Chemical Society of Japan, 1983. ${ }^{6)}$

\section{MATERIALS AND METHODS}

Strains. Yeast strains used and their relevant genotypes are listed in Table I.

Culture media. YPS medium contained $1 \%$ yeast extract, $2 \%$ peptone, and $3 \%$ soluble starch.YPSB medium was YPS medium with the addition of $3.3 \times 10^{-3} \%$ bromocresol purple. YEPD medium contained $1 \%$ yeast extract, $2 \%$ peptone, and $2 \%$ dextrose. If necessary, the media were solidified by $2 \%$ agar. Sporulation plates contained $1 \%$ potasium acetate, $0.1 \%$ yeast extract, $0.05 \%$ dextrose, and $2 \%$ agar.

Fermentation test for starch. Fermentation tests were carried out by the classical Durham-tube method ${ }^{1)}$ as follows: a loopful of cells was innoculated into $5 \mathrm{ml}$ of YPS medium in a test tube $(1.8 \times 18 \mathrm{~cm})$ with a Durham tube, and the test tube stood at $28^{\circ} \mathrm{C}$ for up to 3 weeks.

Flocculation test. Cells were cultured with shaking in a test tube $(1.5 \times 10.5 \mathrm{~cm})$ containing $1 \mathrm{ml}$ of YEPD medium at $28^{\circ} \mathrm{C}$ for $1 \sim 2$ days. The degree of flocculation was estimated first by the appearance of the sedimented cells 
TABle I. Strains

\begin{tabular}{|c|c|c|}
\hline Strain & Genotype $^{a}$ & Source \\
\hline $5104-9 \mathrm{C}$ & $\alpha$ his6 ura3 $S T A 1$ & H. Tamaki \\
\hline $5106-32 \mathrm{D}$ & $\alpha \arg 4$ his 2 lys 2 FLO8 STA1 & H. Tamaki \\
\hline YIY2-11A & a leu2-3,112 his 2 STA 1 & This work \\
\hline YIY2-12D & a leu2-3,112 his 2 lys 2 STA 1 & This work \\
\hline YIY4-6B & a $\arg 4$ lys $2 S T A 1$ & This work \\
\hline YIY11-1B & a leu2-3,112 STA 1 & This work \\
\hline YIY4-3A & $\alpha \arg 4$ his $4 S T A 1$ & This work \\
\hline YIY12-2D & $\alpha$ leu2-3,112 his 2 his4 STA 1 & This work \\
\hline YIY247 & a his4 STA1 & This work \\
\hline YIYD11-7D & $\alpha \arg 4$ lys 2 FLO8 STA 1 & This work \\
\hline YIYD11-9D & $\alpha$ his 2 FLO8 STA1 & This work \\
\hline YIY1-6A & a leu2-3,112 his $4 \mathrm{flo}^{\circ}$ & This work \\
\hline YIY256 & a $\arg 4$ FLO8 STA1 & This work \\
\hline YIY257 & a leu2-3,112 his 2 his4 FLO8 STA1 & This work \\
\hline YIY 258 & a his2 his4 lys 2 FLO8 STA1 & This work \\
\hline YIY260 & a leu2-3,112 his 2 his4 lys 2 FLO8 STA1 & This work \\
\hline YIY262 & a his4 lys 2 FLO8 STA1 & This work \\
\hline YIY268 & $\alpha \arg 4$ FLO8 STA1 & This work \\
\hline YIY269 & $\alpha$ leu2-3,112 arg4 his 2 his 4 lys 2 FLO8 STA 1 & This work \\
\hline YIY271 & a leu2-3,112 his 2 his 4 FLO8 STA1 & This work \\
\hline YIY277 & $\alpha$ his4 FLO8 STA1 & This work \\
\hline YIY280 & a leu2-3,112 his $2 \mathrm{flo}^{\circ}$ & This work \\
\hline YIY281 & a his4 lys $2 \mathrm{flo}^{\circ}$ & This work \\
\hline YIY284 & a leu2-3,112 his $4 \mathrm{flo}^{\circ}$ & This work \\
\hline YIY285 & a leu2-3,112 his4 lys $2 \mathrm{flo}^{\circ}$ & This work \\
\hline YIY292 & $\alpha \operatorname{lys} 2 \mathrm{flo}^{\circ}$ & This work \\
\hline YIY294 & $\alpha$ his 2 his 4 lys 2 flo $^{\circ}$ & This work \\
\hline YIY297 & $\alpha$ leu2-3,112 his 2 his $4 \mathrm{flo}^{\circ}$ & This work \\
\hline YIY299 & $\alpha$ his $4 f^{\circ} o^{\circ}$ & This work \\
\hline YIY223 & a cdc 6 ade 1 ade 2 his 2 his 7 leu 2 met 2 STA 1 flo ${ }^{\circ}$ & This work \\
\hline YIY204 & $\alpha c d c 6$ his4 STA1 FLO8 & This work \\
\hline YIY259 & a leu2-3,112 arg4 STA1 & This work \\
\hline YIY261 & a arg4 his 2 lys 2 STA 1 & This work \\
\hline $5301-17 \mathrm{~B}$ & $\alpha \operatorname{lys} 7 S T A 3$ & H. Tamaki \\
\hline YIYSTA3-2 & a leu2-3,112 his2 his4 STA3 & This work \\
\hline YIYSTA3-3 & a leu2-3,112 his4 STA3 & This work \\
\hline YIYSTA3-5 & a his2 his 4 STA3 & This work \\
\hline
\end{tabular}

a $f l o^{\circ}$ indicates the absence of a flocculation gene in cells; in the asci prepared from the cross $F L O 8 \times f l 0^{\circ}$, the flocculating ability was segregated as 2 (flocculating): 2 (non-flocculating).

and second by the nature of the floc after degradation of the sediment with a Vortex mixer. This method was routinely used for characterization of the flocculating ability in genetic studies.

Protoplast fusion. Diploid strains homozygous for MAT were constructed by the standard protoplast-fusion method $^{7)}$ with selection for prototrophy. Most of the fusants are expected to be diploids, since all of the six fusants examined were estimated to be diploids by tetrad analysis of the hybrids constructed by the crosses between each of the fusants and a standard diploid strain homozygous for $M A T$.
Assay for glucoamylase activity. Cells were cultured in YPS medium at $28^{\circ} \mathrm{C}$ for 3 days. The culture supernatant was obtained by centrifugation, dialyzed extensively against deionized water, and assayed for glucoamylase activity. The reaction mixture (final volume, $0.5 \mathrm{ml}$ ) for the assay contained $0.4 \%$ soluble starch, $80 \mathrm{~mm}$ sodium acetate buffer ( $\mathrm{pH}$ 5.0) and the dialyzed enzyme solution. The reaction mixture was incubated at $50^{\circ} \mathrm{C}$ for $20 \mathrm{~min}$, and the reducing sugar (glucose) formed was determined by the standard Somogyi-Nelson method. ${ }^{2)}$ Under the conditions used here, the activity proceeded linearly at least for $30 \mathrm{~min}$. The activity was presented as increased absorbance at $660 \mathrm{~nm}$ for $20 \mathrm{~min}$ per $0.1 \mathrm{ml}$ of the enzyme 
Table II. Mating-TYPe Regulation of the $S T A$ Genes

\begin{tabular}{|c|c|c|c|c|c|}
\hline \multicolumn{2}{|c|}{ Genotype } & $\begin{array}{r}\text { Strain }^{a} \\
\text { YIY2-11A }\end{array}$ & $\frac{\text { Fermentation }^{b}}{3}$ & $\begin{array}{r}\text { Halo }^{c} \\
+\end{array}$ & $\begin{array}{c}\begin{array}{c}\text { Glucoamylase } \\
\text { activity }\end{array} \\
21.5\end{array}$ \\
\hline$S T A 1$ & $M A T \mathrm{a}$ & $\begin{array}{l}\text { YIY2-11A } \\
\text { YIY2-12D } \\
\text { YIY4-6B } \\
\text { YIY11-1B }\end{array}$ & $\begin{array}{l}3 \\
3 \\
3 \\
3\end{array}$ & $\begin{array}{l}+ \\
+ \\
+ \\
+\end{array}$ & $\begin{array}{l}21.5 \\
13.0 \\
13.5 \\
22.0\end{array}$ \\
\hline$S T A 1$ & $M A T \alpha$ & $\begin{array}{l}\text { YIY4-3A } \\
\text { YIY12-2D } \\
5104-9 C\end{array}$ & $\begin{array}{l}3 \\
3 \\
3\end{array}$ & $\begin{array}{l}+ \\
+ \\
+\end{array}$ & $\begin{array}{l}18.5 \\
17.0 \\
11.0\end{array}$ \\
\hline$S T A 1 / S T A 1$ & $M A T \mathrm{a} / M A T \alpha$ & $\begin{array}{l}\text { YIY2-11A } \times \text { YIY4-3A } \\
\text { YIY2-12D } \times \text { YIY4-3A } \\
\text { YIY11-1B } \times \text { YIY4-3A } \\
\text { YIY4-6B } \times \text { YIY12-2D }\end{array}$ & $\begin{array}{l}13 \\
14 \\
13 \\
20\end{array}$ & $\begin{array}{l}- \\
- \\
- \\
-\end{array}$ & $\begin{array}{l}0.2 \\
0.6 \\
0.5 \\
0.2\end{array}$ \\
\hline$S T A 1 / S T A 1$ & $M A T \mathrm{a} / M A T \mathrm{a}$ & $\begin{array}{l}\text { YIY2-11A × YIY4-6B } \\
\text { YIY11-1B × YIY4-6B } \\
\text { YIY247 × YIY2-11A } \\
\text { YIY247 × YIY2-12D }\end{array}$ & $\begin{array}{l}3 \\
3 \\
3 \\
3\end{array}$ & $\begin{array}{l}+ \\
+ \\
+ \\
+\end{array}$ & $\begin{array}{l}12.0 \\
17.5 \\
13.5 \\
14.0\end{array}$ \\
\hline$S T A 1 / S T A 1$ & $M A T \alpha / M A T \alpha$ & $\begin{array}{l}\text { YIY4-3A } \times 5104-9 C \\
\text { YIY4-3A } \times \text { YIYD11-9D } \\
\text { YIYD11-7D } \times \text { YIYD11-9D } \\
\text { YIYD11-7D } \times \text { YIY12-2D }\end{array}$ & $\begin{array}{l}3 \\
3 \\
3 \\
3\end{array}$ & $\begin{array}{l}+ \\
+ \\
+ \\
+\end{array}$ & $\begin{array}{r}16.0 \\
9.5 \\
8.5 \\
17.5\end{array}$ \\
\hline$S T A 3$ & $M A T \mathrm{a}$ & $\begin{array}{l}\text { YIYSTA3-2 } \\
\text { YIYSTA3-3 } \\
\text { YIYSTA3-5 }\end{array}$ & $\begin{array}{l}4 \\
3 \\
4\end{array}$ & $\begin{array}{l}+ \\
+ \\
+\end{array}$ & $\begin{array}{l}2.0 \\
2.4 \\
1.7\end{array}$ \\
\hline$S T A 3$ & $M A T \alpha$ & $5301-17 \mathrm{~B}$ & 3 & + & 1.8 \\
\hline$S T A 3 / S T A 3$ & $M A T \mathrm{a} / M A T \alpha$ & $\begin{array}{l}\text { YIYSTA3- } 2 \times 5301-17 \mathrm{~B} \\
\text { YIYSTA3-3 } \times 5301-17 \mathrm{~B} \\
\text { YIYSTA3-5 } \times 5301-17 \mathrm{~B}\end{array}$ & $\begin{array}{r}11 \\
7 \\
8\end{array}$ & $\begin{array}{l}- \\
- \\
-\end{array}$ & $\begin{array}{l}0.2 \\
0.3 \\
0.2\end{array}$ \\
\hline
\end{tabular}

a Diploid strains heterozygous for $M A T$ were constructed by sexual mating of the two haploid strains indicated by the cross. Diploid strains homozygous for $M A T$ were constructed by the protoplast-fusion method using the two haploid strains indicated by the cross.

$b$ Numbers presented are culture days required for visible gas formation in a Durham tube.

c + , halo-forming; and - , non-halo-forming.

solution.

Genetic analysis. Genetic techniques including tetrad analysis were described previously. ${ }^{7)}$

\section{RESULTS}

\section{Mating-type regulation of the STA genes}

We used three independent diagnoses for glucoamylase production, 1) direct measurement of glucoamylase activity secreted in the culture medium, 2) fermentation test for starch, and 3) halo formation for a simple estimation of the enzyme activity on a plate. For the halo formation test, a small amount of cells were smeared on a YPSB plate and the plate was incubated at $28^{\circ} \mathrm{C}$ for $4 \sim 6$ days and at $4^{\circ} \mathrm{C}$ for 2 days. Glucoamylase-producing cells formed halos around their colonies, while non-producing cells did not. This method has allowed us to determine glucoamylaseproducing abilities of the large number of cultures that are necessary in genetic studies. Table II summarizes the glucoamylase production in haploid strains carrying either $M A T a$ or $M A T \alpha$ and diploid strains either heterozygous or homozygous for $M A T$. In diploid strains homozygous for STA1 or STA3 but heterozygous for $M A T$, the fermentation 
Table III. Mating-type Regulation of the FLO8 Gene

\begin{tabular}{|c|c|c|c|}
\hline \multicolumn{2}{|c|}{ Genotype } & \multirow{2}{*}{$\begin{array}{r}\text { Strain }^{a} \\
\text { YIY256 }\end{array}$} & \multirow{2}{*}{$\frac{\text { Flocculation }^{b}}{+++}$} \\
\hline FLO8 & $M A T \mathrm{a}$ & & \\
\hline FLO8 & $M A T \alpha$ & 5106-32D & +++ \\
\hline$f l o^{\circ}$ & $M A T \mathrm{a}$ & YIY1-6A & - \\
\hline$f l o^{\circ}$ & $M A T \alpha$ & YIY292 & - \\
\hline \multirow[t]{4}{*}{ FLO8/FLO8 } & $M A T \mathrm{a} / M A T \alpha$ & YIY257 × YIY268 & +++ \\
\hline & & YIY258 × YIY268 & +++ \\
\hline & & YIY260 $\times$ YIY 268 & +++ \\
\hline & & YIY262 × YIY268 & +++ \\
\hline \multirow[t]{4}{*}{ FLO8/FLO8 } & $M A T \mathrm{a} / M A T \mathrm{a}$ & YIY256 × YIY257 & +++ \\
\hline & & YIY256 × YIY 258 & +++ \\
\hline & & YIY256 $\times$ YIY 260 & +++ \\
\hline & & YIY256 $\times$ YIY262 & +++ \\
\hline \multirow[t]{2}{*}{ FLO8/FLO8 } & $M A T \alpha / M A T \alpha$ & YIY268 $\times$ YIY271 & +++ \\
\hline & & YIY268 $\times$ YIY277 & +++ \\
\hline \multirow[t]{3}{*}{$F L O 8 / f o^{\circ}$} & $M A T \mathrm{a} / M A T \alpha$ & YIY $280 \times$ YIY 268 & - \\
\hline & & YIY $281 \times$ YIY 268 & - \\
\hline & & YIY $285 \times$ YIY 268 & - \\
\hline \multirow[t]{4}{*}{$F L O 8 / f l o^{\circ}$} & $M A T \mathrm{a} / M A T \mathrm{a}$ & YIY256 $\times$ YIY 280 & + \\
\hline & & YIY256 × YIY281 & + \\
\hline & & YIY256 × YIY284 & ++ \\
\hline & & YIY $256 \times$ YIY 285 & + \\
\hline \multirow[t]{4}{*}{$F L O 8 / f l o^{\circ}$} & $M A T \alpha / M A T \alpha$ & YIY $268 \times$ YIY 292 & +++ \\
\hline & & YIY268 × YIY294 & ++ \\
\hline & & YIY268 × YIY297 & +++ \\
\hline & & YIY268 $\times$ YIY 299 & ++ \\
\hline
\end{tabular}

a Diploid strains heterozygous for $M A T$ and fusant strains homozygous for $M A T$ were constructed as described in Table II (footnote $a$ ). All strains except 5106-32D and YIY1-6A were derived from the cross 5106-32D $\times$ YIY1-6A which showed 2 (flocculating) : 2 (non-flocculating) segregation.

$b \quad+++$, highly flocculent; ++ , moderately flocculent; + , weakly flocculent; and - , non-flocculent.

ability and the glucoamylase activity were greatly diminished, and halo formation could not be detected. However, in fusant strains homozygous for both STA1 and $M A T$, the glucoamylase production recovered to the level of haploid strains. These results indicate that $M A T a / M A T \alpha$ represses glucoamylase production.

\section{Mating-type regulation of the FLO8 gene}

Table III summarizes the flocculating abilities of haploid strains carrying either $M A T a$ or $M A T \alpha$ and of diploid or fusant strains either homozygous or heterozygous for FLO8 and MAT. In the background of FLO8/FLO8, constitution of the mating type allele did not affect the flocculating ability, however, in the background of $F L O 8 / f o^{\circ}$, diploid strains heterozygous for $M A T$ were non-flocculent, al- though fusant strains homozygous for $M A T$ were flocculent. These results indicate that $M A T a / M A T \alpha$ represses the expression of the FLO8 gene in diploid strains heterozygous for FLO8.

\section{cdc6 Chromosome loss}

To confirm that $M A T a / M A T \alpha$ represses the expression of both $S T A 1$ and FLO8, we constructed, on the basis of mitotic chromosome loss caused by the $c d c 6$ mutation as described by Kawasaki, ${ }^{8}$ a diploid strain YIY237 homozygous for $c d c 6$ and STA1 but heterozygous for $M A T$ and FLO8 by sexual mating of haploid strains YIY223 and YIY204. The diploid strain YIY237 shows neither glucoamylase-producing nor flocculating abilities. Cells of the strain YIY237 were cultured in YEPD medium to $\log$ phase at $28^{\circ} \mathrm{C}$ and 
Table IV. Heat Treatment of the Diploid Strain YiY237 Homozygous for $c d c 6$ AND $S T A 1$ BUT HETEROZYGOUS FOR MAT AND FLO8

\begin{tabular}{|c|c|c|c|c|c|c|c|c|c|c|c|c|c|}
\hline \multirow{2}{*}{ Strain } & \multirow{2}{*}{ Mating type } & \multirow{2}{*}{$c d c 6^{a}$} & \multicolumn{7}{|c|}{ Auxotrophic markers ${ }^{b}$} & \multirow{2}{*}{ Flocculation $^{c}$} & \multirow{2}{*}{ Halo $^{d}$} & \multirow{2}{*}{$\begin{array}{c}\text { Glucoamylase } \\
\text { activity }\end{array}$} & \multirow{2}{*}{$\begin{array}{c}\text { Genotype } \\
\text { of } M A T\end{array}$} \\
\hline & & & ade 1 & ade 2 & his 2 & his 4 & his 7 & leu2 & met 2 & & & & \\
\hline YIY223 & $a$ & - & - & - & - & + & - & - & - & - & + & 7.0 & $M A T \mathrm{a}$ \\
\hline YIY204 & $\alpha$ & - & + & + & + & - & + & + & + & ++ & + & 4.0 & $M A T \alpha$ \\
\hline YIY237 & Non-mater & - & + & + & + & + & + & + & + & - & - & 0.1 & $M A T \mathrm{a} / M A T \alpha$ \\
\hline YIY250 & $a$ & - & + & + & + & + & + & - & + & ++ & + & 7.0 & $M A T \mathrm{a}$ \\
\hline YIY251 & $a$ & - & + & + & + & + & + & - & + & ++ & + & 4.3 & $M A T \mathrm{a}$ \\
\hline YIY248 & $\alpha$ & - & + & + & + & - & + & + & + & ++ & + & 4.0 & $M A T \alpha$ \\
\hline YIY249 & $\alpha$ & - & + & + & + & - & + & + & + & ++ & + & 4.5 & $M A T \alpha$ \\
\hline YIY237-5 & $\alpha$ & - & + & + & + & - & + & + & + & ++ & + & 5.0 & $M A T \alpha$ \\
\hline YIY237-7 & $\alpha$ & - & + & + & + & - & + & + & + & ++ & + & 6.2 & $M A T \alpha$ \\
\hline
\end{tabular}

a (-) indicates temperature-sensitive phenotype.

$b \quad(+)$ indicates prototroph and $(-)$ indicates auxotroph.

c See footnotes in Table III.

d See footnotes in Table II. 
Table V. Ultraviolet Treatment of the Diploid Strains Homozygous FOR $S T A 1$ BUT HETEROZYGOUS FOR $M A T$

\begin{tabular}{|c|c|c|c|c|c|c|c|c|c|c|}
\hline \multirow{2}{*}{ Strain } & \multirow{2}{*}{ Mating type } & \multicolumn{5}{|c|}{ Auxotrophic markers ${ }^{a}$} & \multirow{2}{*}{$\mathrm{Halo}^{b}$} & \multirow{2}{*}{$\begin{array}{c}\text { Glucoamylase } \\
\text { activity }\end{array}$} & \multirow{2}{*}{$\begin{array}{c}\text { Spore } \\
\text { formation }^{c}\end{array}$} & \multirow{2}{*}{$\begin{array}{l}\text { Genotype } \\
\text { of } M A T\end{array}$} \\
\hline & & his 2 & his 4 & leu2 & lys 2 & $\arg 4$ & & & & \\
\hline YIY4-3A & $\alpha$ & + & - & + & + & - & + & 6.4 & - & $M A T \alpha$ \\
\hline YIY259 & $a$ & + & + & - & + & - & + & 5.2 & - & $M A T \mathrm{a}$ \\
\hline YIY261 & $a$ & - & + & + & - & - & + & 6.2 & - & $M A T \mathrm{a}$ \\
\hline $\begin{array}{l}\text { YIY4-3A } \\
\times \text { YIY259 }\end{array}$ & Non-mater & + & + & + & + & - & - & 0.1 & + & $M A T \mathrm{a} / M A T \alpha$ \\
\hline $\begin{array}{l}\text { YIY4-3A } \\
\quad \times \text { YIY261 }\end{array}$ & Non-mater & + & + & + & + & - & - & 0.2 & + & $M A T \mathrm{a} / M A T \alpha$ \\
\hline UV1 & $a$ & + & + & + & + & - & + & 5.6 & - & $M A T \mathrm{a} / M A T \mathrm{a}$ \\
\hline UV2 & $a$ & + & + & + & + & - & + & 5.0 & - & $M A T \mathrm{a} / M A T \mathrm{a}$ \\
\hline UV7 & $a$ & + & + & + & + & - & + & 6.0 & - & $M A T \mathrm{a} / M A T \mathrm{a}$ \\
\hline UV8 & $a$ & + & + & + & + & - & + & 4.0 & - & $M A T \mathrm{a} / M A T \mathrm{a}$ \\
\hline UV3 & $\alpha$ & + & + & + & + & - & + & 4.4 & - & $M A T \alpha / M A T \alpha$ \\
\hline UV4 & $\alpha$ & + & + & + & + & - & + & 5.6 & - & $M A T \alpha / M A T \alpha$ \\
\hline UV10 & $\alpha$ & + & + & + & + & - & + & 5.6 & - & $M A T \alpha / M A T \alpha$ \\
\hline UV11 & $\alpha$ & + & + & + & + & - & + & 5.6 & - & $M A T \alpha / M A T \alpha$ \\
\hline UV13 & $\alpha$ & + & + & + & + & - & + & 3.5 & - & $M A T \alpha / M A T \alpha$ \\
\hline UV6 & $\alpha$ & + & - & + & + & - & + & 6.0 & - & $M A T \alpha$ \\
\hline UV9 & $\alpha$ & + & - & + & + & - & + & 7.4 & - & $M A T \alpha$ \\
\hline UV12 & $\alpha$ & + & - & + & + & - & + & 5.4 & - & $M A T \alpha$ \\
\hline UV5 & Non-mater & + & + & + & + & - & + & 6.2 & + & $M A T \mathrm{a} / M A T \alpha$ \\
\hline
\end{tabular}

a See footnotes in Table IV.

$b$ See footnotes in Table II.

c (+) indicates spore-forming phenotype and (-) indicates non-spore-forming phenotype.

plated on the YPSB plates. The plates were incubated as $35^{\circ} \mathrm{C}$ (a restrictive temperature for the $c d c 6$ mutation) for $6 \mathrm{hr}$ (survival, $10 \%$ ) and then incubated at $28^{\circ} \mathrm{C}$ for 6 days and at $4^{\circ} \mathrm{C}$ for 2 days. Halo-forming colonies were picked up and subcultured to single colonies on the YPSB plate. The clones were examined for mating type, auxotrophic markers, flocculating ability and glucoamylase-producing ability. The results are presented in Table IV. All halo-forming clones produced glucoamylase activity and showed mating ability (either $a$ or $\alpha$ ) and flocculating ability. The clones showing mating type $a$ were leu 2 and the clones showing mating type $\alpha$ were his 4 . These results indicate that one of two chromosomes (III) in the diploid strain YIY237 was lost by the heat treatment $\left(35^{\circ} \mathrm{C}\right)$ and the resulting diploids monosomic for chromosome III showed mating type and thus showed glucoamylase-producing and flocculating abilities.

\section{Treatment with ultra-violet light}

Another approach to confirm the matingtype regulation of the $S T A 1$ gene was carried out on the basis of mitotic recombination or gene conversion, chromosome loss, and mutation caused by ultra-violet (UV) light. Diploid strains homozygous for $S T A 1$ but heterozygous for $M A T$ were constructed by the crosses YIY4-3A $\times$ YIY259 and YIY4$3 A \times$ YIY261. The diploid strains showed no glucoamylase-producing ability. The diploid strains were cultured in YEPD medium to log phase, plated on the YPSB plates and treated with UV light for $30 \mathrm{sec}$ (survival, 10\%). The plates were incubated at $28^{\circ} \mathrm{C}$ for 6 days and at $4^{\circ} \mathrm{C}$ for 2 days. Halo-forming clones were picked up and subcultured to single colonies on the YPSB plate. The clones UV1 to UV8 were obtained from the strain YIY4-3A $\times$ 
YIY259, and the clones UV9 to UV13 were obtained from the strain YIY4-3A $\times$ YIY261. Mating ability, auxotrophic markers, glucoamylase production, and spore-forming ability were examined with these clones. The results are presented in Table V. All clones except UV5 showed mating ability. The auxotrophic markers of the clones indicate the genotypes for $M A T ; M A T a / M A T a$ and $M A T \alpha / M A T \alpha$ may be due to mitotic recombination or gene conversion, and MAT $\alpha$ (monosomic for chromosome III) may be due to chromosome loss. The strain UV5 was a non-mater and showed spore-forming ability, suggesting that the mutation caused by UV light derepressed the $M A T a / M A T \alpha$ repression against $S T A 1$. The strain UV5-3D (MATa) was one of the glucoamylase-producing segregants from the asci prepared from the strain UV5. In the asci prepared from the hybrid constructed by the cross between the strain UV5-3D and a wildtype strain YIY269 (MAT $S T A 1)$, the glucoamylase-producing ability was segregated as 4 (producing): 0 (non-producing). Diploid strains heterozygous for $M A T$, constructed by the crosses between the strain UV5-3D and any one of the wild-type strains carrying STA1, showed glucoamylase-producing ability, suggesting that a dominant mutation against MATa/MAT $\alpha$ repression is present in the strain UV5-3D. Further experiments to characterize this mutation are now in progress.

\section{DISCUSSION}

Our results show that $M A T a / M A T \alpha$ represses the expression of two of the $S T A$ genes (STA1 and $S T A 3)$ and the flocculation gene FLO8. It would be interesting to isolate and characterize the DNA sequences of the $S T A$ and FLO genes, since it is speculated that regulatory regions of the genes may contain a common DNA sequence which accepts mating signals.

Regulatory mutations occurring adjacent to structural genes and causing overproduction of associated gene products have been found in
$S$. cerevisiae. In a class of regulatory mutations at the $C Y C 7, C A R 1, C A R 2, D U R 1,2^{9)}$ and $A D R 3^{10)}$ loci, the overproduction is greatly diminished in diploids that are heterozygous at $M A T$. Moreover, there are several his $4 \mathrm{mu}-$ tations which are subject to $M A T$ control. ${ }^{11)}$ In every case, the mutations are caused by insertion of Ty (transposable yeast) elements at the $5^{\prime}$ non-coding region of the structural genes. It is known that transcription of the Ty elements themselves is repressed in diploid cells heterozygous at $M A T .^{12)}$ However, it is obscure how Ty elements subject genes to $M A T$ control and whether other mechanisms for $M A T$ control are present or not.

Recently, we cloned the $S T A 1$ gene (manuscript No. 3-307, accepted by Agric. Biol. Chem.) and the study using the cloned gene will provide some information on the $M A T$ control, while it is not known what the $M A T$ control against STA and FLO genes means for the growth of yeast cells and in the evolution of $S$. diastaticus and $S$. cerevisiae (manuscript No. 3-333, accepted by Agric. Biol. Chem.).

Acknowledgments. We are grateful to H. Tamaki for providing $S$. diastaticus strains. This investigation was supported in part by a Grant-in-Aid for Scientific Research (Grant No. 00544009) from the Ministry of Education, Science and Culture of Japan.

\section{REFERENCES}

1) H. Tamaki, Mol. Gen. Genet., 164, 205 (1978).

2) H. Tamaki, Ann. Rep. Studies, Doshisha Women's College, 31, 166 (1980).

3) J. Lodder, "The Yeasts," Amsterdam, London, 1970.

4) B. L. A. Miki, N. H. Poon, A. P. James and V. L. Seligy, J. Bacteriol., 150, 878 (1982).

5) G. G. Stewart, Brew. Dig., March, 42 (1975).

6) I. Yamashita, T. Maruyama, K. Fukuhara, K. Suzuki, T. Maemura and S. Fukui, Abstracts of Papers, Annual Meeting of Agric. Chem. Soc. Japan, 1983, p. 352.

7) T. Maemura, I. Yamashita and S. Fukui, FEBS Lett., 158, 50 (1983).

8) G. Kawasaki, Ph. D. thesis, University of Washington, Seattle, Washington, 1979.

9) B. Errede, T. S. Cardillo, F. Sherman, E. Dubois, J. Deschamps and J. Wiame, Cell, 22, 427 (1980).

10) V. M. Williamson, E. T. Young and M. Ciriacy, Cell, 
23, 605 (1981).

11) G. S. Roeder and G. R. Fink, Proc. Natl. Acad. Sci. U.S.A., 79, 5621 (1982).
12) R. T. Elder, T. P. St. John, D. T. Stinchcomb and R. W. Davis, Cold Spring Harbor Symp. Quant. Biol., 45, 581 (1981). 